\title{
NOTE ON AN INHIBITION PERIOD IN THE SEPARATION OF AN EMULSION.
}

By T. C. Nugent, M.Sc.

(A Paper read before The Faraday Society, Monday, November 28, 1921. Professor Alfred W. Porter, F.R.S., President, in the Chair.)

\section{Received October 27, $192 \mathrm{I}$.}

The system investigated was an emulsion of benzene in water containing known amounts of stabiliser, i.e. gelatin or gum arabic. In all cases the benzene content amounted to 50 per cent. (by volume), that is, fairly concentrated emulsions were employed.

Before proceeding to a description of the phenomenon which is referred to in the title as the "inhibition period," the following relatively subsidiary matters may be very briefly recorded.

I. A rapid method of producing concentrated emulsions of $5^{\circ}$ per cent. (by volume) disperse phase was devised. The method consists of adding equal volumes of the gelatin solution and the benzene to a wide tube and gently agitating the tube whilst held horizontally. The benzene is found to take the form of droplets in the gelatin solution. When this stage is reached, one vigorous shake given to the tube is sufficient to produce a good emulsion, which can be made reasonably uniform by a few more vigorous shakes. The concentration of the gelatin solution employed must be $0^{\prime}$ I per cent. or more. The gentle agitation of the tube must be carried on until all the benzene has passed into droplets; if this is not done then on vigorously shaking the tube the two phases separate after a few moments.

2. If a tube of emulsion which is stable to centrifuging at 2000 revolutions per minute is fixed to the spoke of a wheel which is rotated in a vertical plane at a rate of three revolutions per minute no effect is produced if the tube is completely filled with emulsion; but if there is an air space in the tube, then separation of the benzene takes place. The rate of separation under such treatment depends directly upon the size of the air space in the tube.

3. Sulphuric acid even at a concentration of 3.5 normal has scarcely any de-emulsifying effect upon such emulsions.

4. The effect of caustic soda is very marked, a concentration of $0.5 \mathrm{~N} . \mathrm{NaOH}$ causing the complete separation of an emulsion containing 50 per cent. benzene in a gelatin solution of 0.4 per cent. concentration in about an hour.

This separating action of caustic soda cannot be due to the electrical neutralisation of the charges on the emulsoid particles, since these were 
shown to carry a small negative charge. The effect must be due to the destruction or breaking down of the protecting layers; the gelatin being transformed into some less colloidal condition. In connection with this mention might be made of the result obtained by C. R. Smith ${ }^{1}$ who found that gelatin in water had a molecular weight of 96,000 whereas its combining weight with caustic soda is known to be about 7000 .

5. The rate at which the benzene separates from such an emulsion on the addition of caustic soda increases with time. This is probably due to the continuous decrease in the viscosity of the system owing to the separation of the benzene.

\section{The Inhibition Period.}

On examining the addition of caustic soda to such emulsions the following observation was made: If an emulsion is produced and caustic soda solution is added immediately then the separation of the benzene commences immediately; but if an emulsion is produced and left undisturbed for some time before the caustic soda solution is added, it is found that the separation of the benzene is retarded, i.e. inhibited, no separation occurring for some time. This time lag may be termed conveniently the "Inhibition Period". The duration of this period is found to depend upon the length of time which has elapsed between the actual production of the emulsion and the addition of the alkali.

The suggested cause of this phenomenon is, that after an emulsion is produced, the gelatin is slowly forming protecting layers about the benzene particles, and therefore the stability of an emulsion increases with its age. Before the benzene particles can be caused to coalesce these protecting layers must be removed by the caustic soda. As the strength and number of these protecting layers is increased so must the time required for their removal or destruction by the caustic soda be increased.

The phenomenon was first observed whilst using 0.4 per cent. gelatin solution as the emulsifying agent. Consequently on investigating the nature of the phenomenon this concentration was first employed. The caustic soda solution employed was such as to produce in the emulsion a concentration of $0.5 \mathrm{~N}$. NaOH. The results are shown in the following table :-

\section{TABLE I.}

Inhibition Period when Using 0.4 Per Cent. Gelatin Solution.

\begin{tabular}{|c|c|c|c|}
\hline \multicolumn{2}{|c|}{$\begin{array}{l}\text { Age of Emulsion } \\
\text { Before the Addition } \\
\text { of Caustic Soda. }\end{array}$} & \multicolumn{2}{|c|}{ Inhibition Period. } \\
\hline & ours. & o & inutes. \\
\hline 2 & $"$, & 35 & ", \\
\hline 6 & ", & 45 & , \\
\hline r2 & ," & 55 & ", \\
\hline 24 & ," & 60 & , \\
\hline 48 & ," & 70 & , \\
\hline 72 & ," & 75 & ", \\
\hline
\end{tabular}

${ }^{1}$ F. Amer. Chcm. Soc., 1920, 43, 1353 . 
The above data are shown in the following graph:-

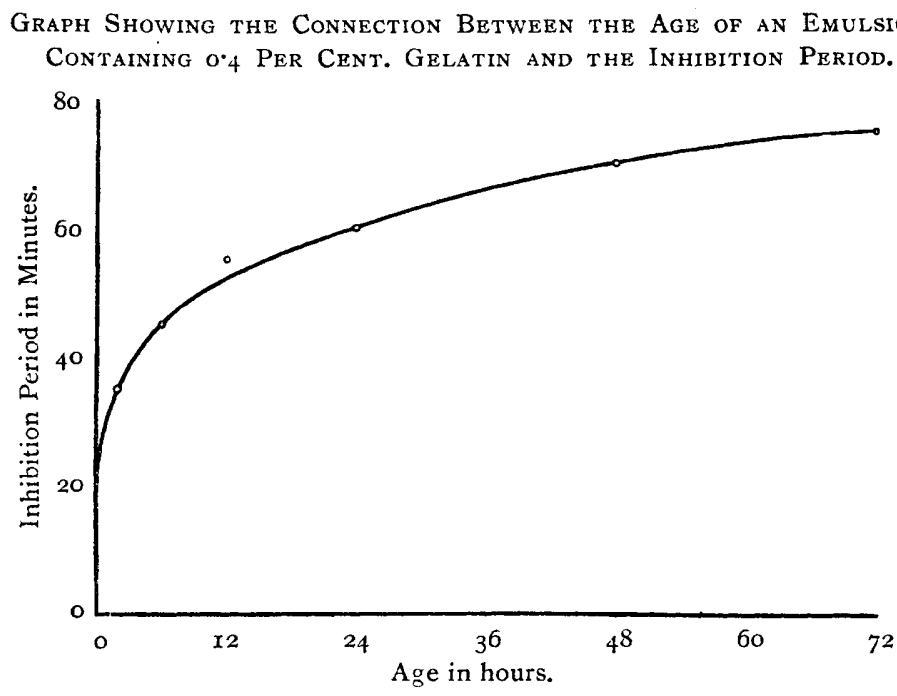

FIG. I.

It will be observed that the experimental points lie chiefly on a smooth curve which is parabolic in shape. This can be shown by plotting the logarithms of "Age" against the logarithms of "Inhibition Period" when a straight line is obtained.

The significance of this form of curve becomes more apparent if we regard the inhibition period as a measure of the time taken for the alkali to remove the layers of the gelatin adsorbed on the benzene globules and therefore a measure of the amount or thickness of the gelatin adsorbed, and the age of the emulsion as the time required to produce a given amount of adsorption. The curve therefore indicates the "rate" at which the emulsifier is being adsorbed. This is believed to be the first measurement of this nature in emulsoid systems.

The equation representing the curve is,

$$
\mathrm{X}=30 \cdot \mathrm{I} \mathrm{r}^{0 \cdot 2135}
$$

where " $\mathrm{X}$ " is the inhibition period and " $y$ " the age of the emulsion.

$$
\text { The rate of adsorption }=d \mathrm{X} / d y=0.2135 \mathrm{X} / y \text {. }
$$

That is, the rate of adsorption depends directly upon the amount already adsorbed and inversely upon the age of the emulsion, i.e. upon the time.

This is a peculiar result, yet it is in agreement with the assumption of the building up of the successive protecting layers about the benzene particles.

The experimental results shown above are not altered by passing the emulsion through a glass homogeniser similar to that suggested by $\mathrm{T}$. $\mathrm{R}$. Briggs. ${ }^{1}$ The homogeniser was altered so that there is an increase of pressure forcing the emulsion through the small orifice instead of evacuating the second vessel as Briggs suggested, since it was found that partial 
evacuation of the second tube caused the benzene to boil; with consequent destruction of the emulsions.

Since the increase in the inhibition period is so small for the last twenty-four hours of standing the reading of seventy-five minutes is taken as the "limiting inhibition period" for a gelatin solution of 0.4 per cent. and 0.5 normal caustic soda.

Employing gelatin solutions of $0.2,0^{\circ} 15$ and 0.12 per cent. concentration respectively together with a standard amount of caustic soda (namely $0.5 \mathrm{~N} . \mathrm{NaOH}$ in the emulsion), the results obtained are shown in the following tables:-

TABLE II.

Concentration of Gelatin Solution 0.2 Per Cent.

Age of Emuision before the Addition of Caustic Soda. Inhibition Period.

o hours. $\quad$ o.minutes.

$\begin{array}{llll}48 & \text { " } & \text { 15 } \\ 67 & , & 25 & , \\ 69 & , & 25 & \end{array}$

Limiting inhibition period $=25$ minutes.

TABLE III.

Concentration Gefatin Solution o.i5 Per Cent.

Age of Emulsion before

the Addition of

Caustic Soda.

Inhibition Period.

o hours. o minutes.

49 " 15 ,"

69, I5 ,

$7 \mathrm{I}$ " 15 ,

Limiting inhibition period $=15$ minutes.

TABLE IV.

Concentration of Gelatin Solution o.xz Per Cent.

Age of Emuision before the Addition of Caustic Soda.

Inhibition Period.

o hours. o minutes.

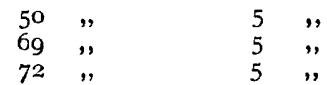

Limiting inhibition period $=5$ minutes.

When using gelatin solution of 0.1 per cent. concentration no inhibition period was found howsoever long the emulsions were left after being prepared before the caustic soda was added.

Summarising Table showing the concentration of gelatin solution employed and the limiting inhibition period found :-

\begin{tabular}{|c|c|c|c|}
\hline \multicolumn{2}{|c|}{$\begin{array}{l}\text { Concentration of the Gelatin } \\
\text { Solution Employed. }\end{array}$} & \multicolumn{2}{|c|}{$\begin{array}{l}\text { Limiting Inhibition } \\
\text { Period. }\end{array}$} \\
\hline $0 \cdot I$ & cent. & & nutes. \\
\hline 0.12 & $"$ & 5 & ", \\
\hline 0.15 & ", & I5 & ," \\
\hline 0.2 & ", & 25 & ," \\
\hline 0.4 & ", & 75 & " \\
\hline
\end{tabular}


Readings were only taken to the nearest five minutes. A graph is shown in which these values are represented.

\section{Graph Showing the Connection Between the Limiting Inhibition Period} and the Concentration of Gelatin in the Emulsions.



FIG. II.

It will be observed that these experimental values lie on a straight line.

The significance of the Limiting Inhibition Period on the basis of the view put forward above is that we are here dealing with the final equilibrium quantity adsorbed from the corresponding concentrations of gelatin in the bulk of the continuous phase. Denoting by $\mathrm{X}_{o}$ the final equilibrium quantity adsorbed, we can write-

$$
\mathrm{X}_{o}=\mathrm{KC}_{\text {initial }}
$$

where $\mathrm{C}_{\text {initial }}$ denotes the bulk concentration of the gelatin solution as initially prepared. 